\section{AB0495 INCREASED WORK LOSS DURING PREGNANCY IN WOMEN WITH SYSTEMIC LUPUS ERYTHEMATOSUS COMPARED TO MATCHED HEALTHY CONTROLS}

Birgit Blomjous ${ }^{1}$, Marieke Ter Wee ${ }^{2}$, Alexandre Voskuyl ${ }^{1}$, Hanneke de Vries ${ }^{3}$, Irene E.M. Bultink ${ }^{1}{ }^{1}$ Amsterdam UMC, Vrije Universiteit Amsterdam, Amsterdam Rheumatology and immunology Center, Amsterdam, Netherlands; ${ }^{2}$ Amsterdam UMC, Vrije Universiteit Amsterdam, Amsterdam Rheumatology and immunology Center and Epidemiology and Biostatics, Amsterdam, Netherlands; ${ }^{3}$ Amsterdam UMC, Vrije Universiteit Amsterdam, Obstetrics and Gynecology, Amsterdam, Netherlands

Background: Women with systemic lupus erythematosus (SLE) might be more vulnerable to reduce or stop working during pregnancy because of the increased risk of pregnancy complications compared to the general population. However, no data on work loss during pregnancy and return to work after maternity leave in patients with SLE are available.

Objectives: We aimed to investigate several work outcomes during and after pregnancy in women with SLE compared to matched pregnant controls.

Methods: A case-control study on employment was performed in pregnant women with SLE and matched controls. Matching criteria were age, year of delivery, and number of living infants. Employment was defined as having $\geq 8$ hours/week of paid work before conception. Four work outcomes were investigated: interruption of work for $>1$ week during pregnancy, complete cessation of work for $>1$ week until delivery, reduction in working hours during pregnancy, and the time in weeks to return to work after maternity leave.

Results: A total of 42 women were included (21 SLE patients, 21 controls). Mean SELENA-SLEDAI before pregnancy in SLE patients was 2.6 (SD 2.3). Interruption of work for $>1$ week or completely stop working during pregnancy occurred in 10 SLE women, compared to 2 controls $(\mathrm{OR}=8.6,95 \% \mathrm{Cl}$ [1.6-46.8], $\mathrm{p}=0.012)$. From the women who completely stopped working until delivery $(n=8), 7$ women had SLE (OR=1.4, 95\% $\mathrm{Cl}$ [0.07-28.1], $\mathrm{p}=0.826)$. In addition, in women continuing work, reduction of working hours occurred in 5 women with SLE versus 3 controls (OR=1.9, 95\% Cl [0.4-9.1], $\mathrm{p}=0.436$ ).

After delivery, the median (IQR) duration of return to work after maternity leave was 4 weeks after maternity leave $(0-6.8)$ for women with SLE and 2 weeks later $(0-4)$ for controls (Mann-Whitney $U$ test; $p=0.977$ ). No difference in number of women with delay of return to work after maternity leave (yes/no) was found between women with SLE and controls ( $n=9$ versus $n=11$, respectively; OR=1.0, 95\% Cl [0.3-3.7], $p=0.973$ ). Conclusion: Pregnant women with SLE more frequently completely stop working or reduce working hours compared to matched healthy controls. These findings warrant improved counseling of these women and attention of health care providers, including company doctors.

Disclosure of Interests: Birgit Blomjous Speakers bureau: UCB Pharma BV, Marieke ter Wee Grant/research support from: Nonrestricted grant from Lilly Netherlands BV, Speakers bureau: ARC Preceptorship program, Alexandre Voskuyl: None declared, Hanneke de Vries Grant/research support from: Pfizer, Speakers bureau: UCB Pharma BV, Irene E.M. Bultink Consultant for: Consultant fee from Sanofi Genzyme, Speakers bureau: Speaker fees from Lilly Netherlands BV, MSD Corp, Amgen BV, UCB Pharma BV, Roche Netherlands BV and Sanofi Genzyme DOI: 10.1136/annrheumdis-2019-eular.2981

\section{AB0496 18F-FDG-PET/CT, 11C-METHIONINE-PET/CT AND MULTI- PARAMETRIC MRI IN THE EVALUATION OF DISEASE ACTIVITY AND GLAND FUNCTION IN PRIMARY SJÖGREN'S SYNDROME}

Michele Bombardieri ${ }^{1}$, Coziana Ciurtin ${ }^{2}$, Michalis Kostapanos ${ }^{3,4}$, Elisa Astorri ${ }^{1}$, Anwar Tappuni ${ }^{1}$, Natasha Jordan ${ }^{3}$, Saleem Azeem ${ }^{5}$, Teresa Fuller ${ }^{6}$, Kathleen Port ${ }^{6}$, Nirav Ratia ${ }^{6}$, Andre van Maurik ${ }^{6}$, Calum Gray ${ }^{7}$, Lucy Kershaw ${ }^{7}$, Rob Janiczek ${ }^{6}$, Graham Searle ${ }^{5}$, Paul Galette ${ }^{6}$, Marius de Groot ${ }^{6}$, Neel Patel ${ }^{6}$, Nicolas Wisniacki ${ }^{6}$, Mats Bergstrom ${ }^{6}$, Pilar Jimenez-Royo ${ }^{6}$, Ruth Tarzi ${ }^{6} .{ }^{1}$ Queen Mary University of London, London, United Kingdom; ${ }^{2}$ University College London, London, United Kingdom; ${ }^{3}$ Addenbrooke's Hospital, Cambridge, United Kingdom; ${ }^{4}$ GSK, Cambridge, United Kingdom; ${ }^{5}$ Invicro, London, United Kingdom; ${ }^{6}$ GSK, Stevenage, United Kingdom; ${ }^{7}$ University of Edinburgh, Edinburgh, United Kingdom

Background: Saliva and tear flow rates and minor salivary gland biopsy are typically used to assess gland function and disease activity in primary Sjögren's syndrome (pSS); however, these have limitations. Imaging methods can directly visualize and generate quantitative values in individual glands. ${ }^{18} \mathrm{~F}$-FDG-PET/CT $\left({ }^{18} \mathrm{~F}\right.$-FDG) measures glucose metabolism, a potential surrogate for inflammation; ${ }^{11} \mathrm{C}$-methionine-PET/CT $\left({ }^{11} \mathrm{C}\right.$-met) is an amino acid PET tracer that assesses protein synthesis, a potential surrogate for gland synthetic function.
Objectives: Explore the potential of molecular imaging and multi-parametric MRI to characterize and quantify pSS disease manifestations.

Methods: In this pilot imaging study (203818), patients with pSS diagnosed per AECG criteria, with a EULAR Sjögren's syndrome disease activity index score $\geq 5$, and basal salivary flow $>0.0 \mathrm{~mL} / \mathrm{min}$ or stimulated salivary flow rate $\geq 0.05 \mathrm{~mL} / \mathrm{min}$, underwent ${ }^{18} \mathrm{~F}$-FDG and ${ }^{11} \mathrm{C}-$ met and dynamic contrast-enhanced and diffusion-weighted MRI, followed by minor salivary gland biopsy for histological analysis. Age- and sexmatched healthy volunteers (HV) underwent MRI and ${ }^{11} \mathrm{C}$-met. HV-pSS mean differences (m-diff; 95\% confidence intervals [CI]) were calculated and Pearson's correlation coefficients $(r)$ estimated. Peak PET standard uptake values (SUVpeak) were used in the correlations and SUVmax values were recorded. All methods were compared with routine clinical and laboratory tests.

Results: 12 patients had MRI, ${ }^{18} \mathrm{~F}-\mathrm{FDG}$ and ${ }^{11} \mathrm{C}$-met; while HV $(\mathrm{n}=12)$ had MRI $(\mathrm{n}=12)$ and ${ }^{11} \mathrm{C}$-met $(\mathrm{n}=8)$. A lower ${ }^{11} \mathrm{C}$-met SUVpeak was seen in the parotid (m-diff: $1.4 \mathrm{~g} / \mathrm{mL}[0.4,2.3])$ and submandibular $(\mathrm{m}$ diff: $2.0 \mathrm{~g} / \mathrm{mL}[0.9,3.2])$ glands in pSS versus $\mathrm{HV}$, as was a trend for lower lacrimal gland uptake (m-diff: $0.5 \mathrm{~g} / \mathrm{mL}[-0.2,1.3]$ ) in patients with pSS. On structural MRI, the fat fraction (mean\%) was higher in pSS vs HV in the submandibular glands (m-diff: $-14.8[\mathrm{Cl}:-29.3,-0.4]$ ), with similar trends observed in the parotid glands $(-11.2[-24.3,1.9])$. There was a negative correlation between ${ }^{11} \mathrm{C}$-met uptake and fat fraction $(r:-0.7$ [$0.9,-0.4])$ in the combined parotid glands. There was positive correlation between ${ }^{11} \mathrm{C}$-met uptake and stimulated salivary flow ( $\mathrm{r}: 0.5[0.03,0.8]$ ) and negative correlation for stimulated salivary flow and fat fraction ( $r$ : $0.5(-0.8,-0.1)]$ in the parotid glands; similar correlations were also seen in the submandibular glands. There was negative correlation between the global lymphoid aggregation score on minor salivary gland biopsy and the combined salivary gland fat fraction ( $\mathrm{r}:-0.7[-0.9,-0.2])$. Parotid gland SUVmax ${ }^{18} \mathrm{~F}$-FDG uptake was higher than historical control values (mean: $1.9 \mathrm{~g} / \mathrm{ml}$, [SD: 0.5$]^{1}$ ) in some patients (pSS mean SUVmax: $2.8 \mathrm{~g} / \mathrm{mL}$ [SD: 0.8 , range 1.7-4.6]), with positive correlation between ${ }^{18} \mathrm{~F}-\mathrm{FDG}$ and ${ }^{11} \mathrm{C}$-met uptake ( $\mathrm{r}: 0.7[0.2,0.9]$ ) in the combined salivary glands.

Conclusion: Imaging showed clear differences between pSS and HV and correlated with clinical endpoints. Low ${ }^{11} \mathrm{C}$-met uptake and high fat fraction on MRI may indicate poor residual gland function, while high ${ }^{18} \mathrm{~F}$ FDG and stable ${ }^{11} \mathrm{C}$-met uptake may define a subpopulation that responds well to anti-inflammatory therapies.

\section{REFERENCES}

[1] Basu S, et al. Nucl Med Commun 2008; 29:367-73.

Acknowledgement: Study/editorial support by Fishawack Indicia Ltd, UK funded by GSK.

Disclosure of Interests: Michele Bombardieri Grant/research support from: Celgene, Consultant for: Medimmune, Coziana Ciurtin: None declared, Michalis Kostapanos Consultant for: Is an NHS consultant seconded to the GSK Clinical Cambridge Unit (50\%) and has nothing to disclose., Elisa Astorri: None declared, Anwar Tappuni: None declared, Natasha Jordan: None declared, Saleem Azeem Shareholder of: GSK, Teresa Fuller Shareholder of: GSK, Employee of: GSK, Kathleen Port Shareholder of: GSK, Employee of: GSK, Nirav Ratia Shareholder of: GSK, Employee of: GSK, Andre van Maurik Shareholder of: GSK, Employee of: GSK, Calum Gray: None declared, Lucy Kershaw: None declared, Rob Janiczek Shareholder of: GSK, Employee of: GSK, Graham Searle: None declared, Paul Galette Shareholder of: GSK, Employee of: GSK, Marius de Groot Shareholder of: GSK, Employee of: GSK, Neel Patel Shareholder of: GSK, Employee of: GSK, Nicolas Wisniacki Shareholder of GSK, Employee of: GSK, Mats Bergstrom Shareholder of: GSK, Consultant for: acted as external consultant to GSK, Employee of: GSK, Pilar Jimenez-Royo Shareholder of: GSK, Employee of: GSK, Ruth Tarzi Shareholder of: GSK, Employee of: GSK DOI: 10.1136/annrheumdis-2019-eular.7050

\section{AB0497 SERUM CALPROTECTIN IN SYSTEMIC LUPUS ERYTHEMATOSUS: IS IT A GOOD ACTIVITY BIOMARKER?}

Jordi Camins-Fàbregas, Melania Martínez-Morillo, Aina Teniente-Serra, Annika Nack, Ivette Casafont-Solé, Laia Gifre, Maria Aparicio-Espinar, Anne Riveros, Águeda Prior-Español, Anahy Brandy-Garcia, Clara SangüesaGomez, Susana Holgado, Lourdes Mateo, Eva Martinez-Cáceres, Alejandro Olive. Hospital Universitari Germans Trias i Pujol, Badalona, Spain

Background: Clinical manifestations of systemic lupus erythematosus (SLE) and infections sometimes are difficult to distinguish. In clinical practice low complement and anti(ds)DNA levels are used to assess lupus activity but 
its determination usually requires some days. Leukocyte count, CRP and ESR cannot discriminate SLE from infectious processes. Calprotectin could be a good biomarker to assess lupus activity since it is more specific than CRP and ESR and faster to analyse than anti(ds)DNA.

Objectives: Our aim is to determine serum calprotectin levels in patients with SLE, and its correlation with analytical and clinical manifestations, especially with disease activity

Methods: A total of 148 patients were included. All patients included fulfilled the SLE criteria (SLICC 2012). A quantitative ELISA analysis was performed to assess levels of serum calprotectin (CALPRO AS, Norway). Other biomarkers of lupus disease activity were also assessed (levels of anti(ds)DNA, hypocomplementemia, ESR and CRP). Clinical variables and activity/damage index (SLEDAI/SLICC) were also evaluated. The study was approved by the Clinical Research Ethics Committee of the hospital and all patients signed an informed consent. The results were compared with a healthy control group of similar age and sex $(n=20)$.

Results: 134 patients (92\%) were women with a mean age of $46 \pm 12$ years and an average SLE evolution of $12 \pm 7$ years. Mean SLEDAI was $2 \pm 2$ (105 inactive [<3], 43 mild [4-12], 0 severe [>13]). Mean SLICC was $0.31 \pm 0.70$. No significant differences were observed in serum calprotectin levels between patients with SLE and healthy controls $(2.93 \pm 2.35$ vs 2.17 $\pm 1.49 \mu \mathrm{g} / \mathrm{mL}, \quad \mathrm{p}=0.160)$. Calprotectin was positively correlated with CRP $(r=0.447, p=<0.001)$ and leukocyte count $(r=0.462, p=<0.001)$. Additionally, patients with higher anti(ds)DNA levels $(>100 \mathrm{UI} / \mathrm{mL})$ had higher calprotectin compared to patients with lower anti(ds)DNA (3.20 \pm 2.63 vs $2.42 \pm 1.57$ $\mu \mathrm{g} / \mathrm{mL} ; \mathrm{p}=0.027$ ), however this pattern was not observed with hypocomplementemia. Contrary to what we expected, we did not observe significant differences on calprotectin levels depending on SLEDAI index classification (cutoff at 4 and 12). Moreover, no differences were observed on calprotectin levels between those patients with/without clinical manifestations such as serositis, arthritis or glomeruloneprhitis. Patients with antiphospholipid antibodies had higher calprotectin levels $(3.75 \pm 2.04$ vs $2.77 \pm 2.38 \mu \mathrm{g} / \mathrm{mL} ; \mathrm{p}=0.045)$.

Conclusion: Serum calprotectin levels were positively correlated with CRP levels and leukocyte count. Patients with higher anti(ds)DNA levels had higher calprotectin levels, however we did not observe significant differences depending on SLEDAI index or the presence of arthritis, serositis neither glomerulonephritis. Even that calprotectin determination is faster than anti(ds)DNA levels and could be helpful in assessing inflammatory activity. There is an interesting relation between antiphospholipid antibodies and calprotectin. This study should be continued in a larger sample of active SLE patients to assess its utility in clinical practice as a discriminating biomarker for flares and even infection

Disclosure of Interests: None declared

DOI: 10.1136/annrheumdis-2019-eular.2295

\section{AB0498 GYNECOLOGICAL SYMPTOMS AND SEXUALITY IN SJOGREN'S SYNDROME}

Özlem Özdemir Işık, Ayten Yazici, Ayse Cefle. Kocaeli University School of Medicine, Internal Medicine, Division of Rheumatology, Kocaeli, Turkey

Background: Patients with Sjogren's syndrome (SS) have symptoms such as vaginal dryness and dyspareunia.

Objectives: In this study we aimed to present of primary SS (pSS) and secondary SS (sSS) patient's gynecological symptoms and effects of the disease on sexuality.

Methods: 60 pSS, 42 sSS, 52 healthy controls $(\mathrm{HC})$ were interviewed. It was asked questions about sexuality, SF-36, HAD scale, pSS and sSS patients were also administered $\mathrm{HAQ}$ and Modified Hiil questionnaire ${ }^{1}$.

Results: The mean age of the patients was $52 \pm 11$ years in the pSS, $54 \pm 11$ years in the SSS and $46 \pm 9$ years in the HC. Although there was no significant difference in term of age in pSS and sSS groups, mean age was lower in $\mathrm{HC}$ group. There were no significant differences in SF-36 mental index score, SF-36 physical index score, HAD-Anxiety score and HAD-Depression score among 3 groups. $62 \%$ of patients in the pSS, $79 \%$ in the sSS and $33 \%$ in $\mathrm{HC}$ were in menopause. Vaginal and vulvar dryness were significantly higher in SS, especially in the pSS than HC. The proportion of sexually active women was lower in sSS group. Spontaneous genital pain and dyspareunia were found to be high in pSS and it was statistically significant. Decreased sexual desire was significantly higher in SS groups (Table1).

HAQ score was significantly lower in pSS group than sSS group. Dyspareunia, dysuria, vaginal dryness and fatigue were significantly higher in pSS (Table2). There was no significant difference between two groups in terms of the effect of vulvar, vaginal dryness, dyspareunia, decreased sexual desire, myalgia, arthralgia and fatigue on sexuality
In the pSS group, it was seen that disease had a negative effect on sexuality. There were no significant differences between the two groups when asked whether they enjoyed sexuality and the sexual problems create problems between their partners. In both groups, $97 \%$ of patients stated that they had not been questioned about their sexuality before $80 \%$ of pSS patients and $88 \%$ of sSS patients stated that they did not talk about sexuality problems.

Conclusion: Gynecological and sexual problems are seen in SS patients. Menopause also contributes to this situation. Patients should be informed about these problems and directed to gynecologists when necessary, and enough time should be reserved as we do.

Table 1. Groups Data

\begin{tabular}{lcccc}
\hline $\mathrm{N}(\%)$ & $\begin{array}{c}\text { Primary SS } \\
(60)\end{array}$ & $\begin{array}{c}\text { Secondary SS } \\
(42)\end{array}$ & $\begin{array}{c}\text { Healthy Control } \\
(52)\end{array}$ & $\mathrm{p}$ \\
\hline Age & $52 \pm 11$ & $54 \pm 11$ & $46 \pm 9$ & $\underline{0.001}$ \\
Menopausal state & $37(62)$ & $33(79)$ & $17(32)$ & $\underline{0.000}$ \\
Menopause Age & $47 \pm 5$ & $48 \pm 4$ & $45 \pm 4$ & 0.722 \\
Hormone replacement & $8(13)$ & $3(7)$ & $3(6)$ & 0.334 \\
therapy & & & & \\
Sexual activity & $46(77)$ & $25(60)$ & $43(83)$ & $\underline{0.033}$ \\
Vaginal dryness & $38(63)$ & $18(43)$ & $11(21)$ & $\underline{0.000}$ \\
Vulvar dryness & $26(43)$ & $17(41)$ & $8(15)$ & $\underline{0.004}$ \\
Dyspareunia & $34(57)$ & $14(33)$ & $16(31)$ & $\underline{0.010}$ \\
Spontaneous genital pain & $17(28)$ & $5(12)$ & $5(10)$ & $\underline{0.019}$ \\
Reduced sexual desire & $44(73)$ & $34(81)$ & $26(50)$ & $\underline{0.003}$ \\
SF-36 mental index & $43.5 \pm 10$ & $45 \pm 12$ & $47 \pm 9$ & 0.237 \\
SF-36 physical index & $43 \pm 11$ & $43 \pm 10$ & $45 \pm 9$ & 0.537 \\
HAD- Anxiety & $7 \pm 4$ & $7 \pm 5$ & $7 \pm 4$ & 0.879 \\
HAD- Depression & $5 \pm 4$ & $5 \pm 5$ & $5 \pm 4$ & 0.824 \\
\hline
\end{tabular}

Table 2. Brief Survey Results of Primary and Secondary Sjögren Patients

\begin{tabular}{lccc}
\hline $\mathrm{N}(\%)$ & $\begin{array}{c}\text { Primary } \\
\mathrm{SS}\end{array}$ & $\begin{array}{c}\text { Secondary } \\
\mathrm{SS}\end{array}$ & $\mathrm{p}$ \\
\hline Vaginal dryness & $38(63)$ & $18(43)$ & $\underline{0.041}$ \\
Vulvar dryness & $26(43)$ & $17(41)$ & 0.774 \\
Dyspareunia & $34(57)$ & $14(33)$ & $\underline{0.020}$ \\
Spontaneous genital pain & $17(28)$ & $5(12)$ & $\underline{0.047}$ \\
Dysuria & $13(22)$ & $2(4.8)$ & $\underline{0.018}$ \\
Dysuria & $44(73)$ & $34(81)$ & 0.372 \\
At least one gynecological & $49(82)$ & $34(81)$ & 0.927 \\
symptom & & & \\
Arthralgia & $33(55)$ & $23(55)$ & 0.981 \\
Myalgia & $38(63)$ & $23(55)$ & 0.385 \\
Fatigue & $48(80)$ & $26(62)$ & $\underline{0.044}$ \\
At least 1 muscle-skeletal symptom & $47(78)$ & $27(64)$ & 0.118 \\
HAQ & $0.19 \pm 0.33$ & $0.45 \pm 0.82$ & $\underline{0.013}$ \\
\hline
\end{tabular}

\section{REFERENCES}

[1] S. Maddali Bongi at all.Gynaecological Symptoms and Sexual Disability in Women with Primary Sjögren's Syndrome and Sicca Syndrome.Clinical and Experimental Rheumatology 2013; 31: 683-690

Disclosure of Interests: None declared

DOI: 10.1136/annrheumdis-2019-eular.3073

\section{AB0499 FINGERSTICK BLOOD TRANSCRIPTOMICS: A PATIENT- CENTRIC APPROACH TO ENABLE PRECISION MEDICINE?}

Matteo Cesaroni ${ }^{1}$, Jessica Schreiter ${ }^{1}$, Loqmane Seridi ${ }^{1}$, Jarrat Jordan ${ }^{1}$, Marc Chevrier ${ }^{1}$, Nando Bansal ${ }^{1}$, Theresa Pattery ${ }^{2}$, Jorge Villacian ${ }^{2} .{ }^{1}$ Janssen Research and Development, LLC, Spring House, United States of America; 2 Janssen Diagnostics, LLC, Raritan, United States of America

Background: Venous blood collection using PAXgene RNA blood stabilization (PAX) is a routine method to obtain blood for gene expression (GE) analysis requiring phlebotomy and cold chain transport. DxCollect is a fingerstick blood micro collection device (MCD) that circumvents phlebotomy and is reported to stabilize blood RNA for up to 14 days at ambient temperature potentially enabling collected blood to be shipped by mail.

Objectives: We evaluated DxCollect ${ }^{\oplus}$ as an alternative to the conventional method to potentially improve convenience and cost effectiveness of blood transcriptomic analysis and allow high frequency transcriptomic assessment.

Methods: Heparinized blood samples were treated with interferon- $\alpha$ for $3 \mathrm{~h}$ in vitro and transferred to 3 PAX and 3 MCD tubes. One PAX and 